\title{
Prospek Budidaya Kerang Darah (Anadara granosa) untuk Peningkatan Produktifitas Tambak di Kecamatan Tugu Semarang
}

\author{
Chrisna Adhi Suryono*, Irwani dan Baskoro Rochaddi \\ Jurusan IImu Kelautan, Fakultas Perikanan dan IImu Kelautan, Universitas Diponegoro. \\ JI. Prof. Soedarto, SH. Kampus UNDIP Tembalang, Semarang 50275 \\ Email : chrisna_as@yahoo.com
}

\begin{abstract}
Abstrak
Tujuan dari kegiatan ini adalah: meningkatkan produktifitas tambak kurang produktip dengan budidaya kerang darah. Metodologi pemecahan masalah yang digunakan adalah mengubah sistim budidaya monokultur menjadi sistim polikultur dua jenis komoditas yang berbeda yang dapat dibudidayakan secara bersamaan dalam satu tambak. Hasil kegiatan menunjukan mitra kerja (petambak) sangat berantusias untuk mengikuti kegiatan tersebut terlihat dari cara mereka yang mengubah sitim budidaya tambak dari monokultur ke polikultur kerang darah. Setelah mengikuti cara sistim polikultur petambak nampak puas dengan hasil peliharaannya karena kedua jenis biota dapat hidup bersama dan menunjukan pertumbuhan yang baik. Dari hasil kegiatan pengabdian ini dapat disimpulkan bahwa sistim budidaya polikultur .dapat meningkatkan produktifitas tambak.
\end{abstract}

Kata kunci: Tambak, kerang dan produktifitas

\begin{abstract}
Abstrack
The aim of the activities was increasing productivity on unproductive brackishwater pound to change the culture system to culture cockle Anadara granosa. The method used to solve the problem was to change the system cultivation from monoculture to be poly-culture two different species which can live and cultivate together in one brackishwater pound.The result shows, the partners was very serious followed all the instruction cultivation process. It can be seen he has change the system of the monoculture cultivation to be poly-culture system which introduce two different species. The result of program showed the farmer (petambak) was very sustified cause of the species can lives together and shows the increasing of weight. The conclusion of the activities was the poly-culture system can improve brackishwater pound productivity.
\end{abstract}

Key words: brakishwater pound, cockle and productivity

\section{PENDAHULUAN}

Mangkang Wetan dan Mangunharjo merupakan Desa Kecamatan di Tugu Kota Semarang yang berbatasan dengan laut pantainya bertambak tradisional dan sebagian besar penduduknya sebagai petambak dan buruh tambak. Beberapa tahun terakhir ini usaha tambak banyak mengalami masalah yaitu dengan semakin meningkatnya intensitas penyakit maupun pencemaran terlebih pada masim kemarau yang ekstrim seperti yahun 2012, dimana suhu air tambak bisa mencapai $30^{\circ} \mathrm{C}$ pada siang hari dan salinitas diatas 33 ppt. Kondisi ini tentunya tidak memberi dampak negatip untuk organisme yang ada didalam tambak seperti vadang dan bandeng. Salah satu alternatip mengatasi hal tersebut dengan membudidayakan organisme yang tahan terhadap suhu dan salitas tinggi. Salah satu organisme yang cocok untuk hidup di tambak dengan salinitas tinggi adalah kerang darah dan dapat diupayakan secara polikultur/ tumpang sari dengan organisme lain. 
Polikultur adalah mengusahakan atau membudidayakan organisme yang bebeda jenis pada lahan yang sama (Kusnedar dan Sudjiharno, 1999).

Budidaya secara polikultur lebih menguntungkan karena luasan lebih efisien, pemanfatan sisa pakan, peningkatan pendapatan (Asnan, dkk, 1998). Lebih lanjut Chrisna dkk (2011) menginformasikan tambak tambak yang tidak produktip dapat dibudidayan secara polikultur antara kerang, rumput laut dan ayam yang kandangya ada diatas tambak sebagai pemasok bahan organik. Kerang darah Anadara granosa secara alami banyak di jumpai di sekitar muara sugai sehingga sangat memungkinkan untuk hidup dan tumbuh di tambak. Hal tersebut dikarenakan kerang memiliki toleransi yang tinggi terhadap salinitas perairan, yaitu berkisar antara $14-30 \mathrm{ppt}$ dengan kedalam perairan berkisar antara 1 - 2 meter dan ketebalan lumpur $20-60 \mathrm{~cm}$ (Laverack dan Dando,1974). Lebih lanjut Prins (1996) mengatakan bahwa habitat kerang darah adalah pada substrat yang terdiri dari fraksi silt dan clay yang mengandung bahan organik 6-11\%.

Pentingnya bahan organik untuk kerang adalah sebagai salah satu sumber makanan karena kerang derah merupakan deposit feeder (Kastoro, 1988). Maka dari itu pembudidayaan kerang darah sangat sesuai untuk dibudidayakan ditambak sebagai alternatif pada saat musim kemarau karena tingginya daya adaptasi jenis organisme tersebut, hal ini sebagai ide dalam pengabdian masyarakat yang dilakukan di Desa desa pesisir seperti di Kecamatan Tugu Kota Semarang.

\section{MATERI DAN METODE}

Berdasarkan permasalahan yang ada maka metodologi pemecahan yang digunakan adalah: Mengubah sistim budidaya dari monokultur (udang atau bandeng) ke polikultur dengan menebar 2 jenis komoditas yang berbeda. Dengan komoditas yang berbeda dengan pertumbuhan yang berbeda dan dengan harga yang bebeda dan masa panen yang bebeda diharapkan dapat meningkatkan produktifitas dan pendapatan petambak. Adapaun prosedur budidaya secara polikultur adalah sebagai berikut:

- Penyuluhan tentang tata cara budidaya polikultur kerang dan dan organisme lain (udang/ bandeng)

- Penyiapan tambak seluas $3000 \mathrm{~m}^{2}$ dengan pendalaman carent, pemberian pembatas dengan waring,

- Penebaran bibit kerang 1000kg/ $3000 \mathrm{~m}^{2}$,

- Pemantauan jalanya kegiatan, maupun pengukuran pertumbuhan kerang.

\section{HASIL DAN PEMBAHASAN}

Hasil kegiatan dimulai dengan observasi lapangan di lokasi pertambakan Desa Mangunharjo Kecamatan Tugu Kota Semarang. Tambak yang digunakan dalam kegiatan ini milik kelompok tambak Kali Santen. Hasil evaluasi terhadap calon tambak yang akan digunakan menunjukan bahwa tambak didaerah tersebut selalu mengalami pergantian air dengan lancar melalui irigasi tambak yang ada melalui pasang surut. Sirkulasi yang lancar pada tambak tersebut sangat cocok untuk budidaya organisme dalam tambak karena tersedianya oksigen yang cukup, pasokan nutrien yang lancar dan menjaga kwalitas air yang ada.

Hasil pengamatan terhadap kwalitas air menunjukan salitas pada bulan September antara 29 - 32 ppt, suhu air $26^{\circ} \mathrm{C}$, dan kandungan oksiger terlarut berkisar antara 4,6 - 5,3 ppm, pH 7,2, kedalaman tambak saat surut $60 \mathrm{~cm}$ sedangkan saat pasang $125 \mathrm{~cm}$. Dasar tambak lumpur berpasir dengan kedalaman lumpur antara $30-50 \mathrm{~cm}$. Kondisi pertambakan yang demikian sangat cocok untuk budidaya tambak baik untuk pemeliharaan kerang (Bardach, dkk., 1976., Prins, 1996,. Laverack dan Dando, 1974., Anonimus, 2003).

Hasil survey lapangan yang menunjukan kecocokan lahan untuk 
budidaya kerang darah Anadara ganosa secara polikultur maka kegiatan selanjutnya adalah survey pencarian bibit kerang. Bibit kerang didapatkan dari pengepul bibit kerang di Desa Menco Kecamatan Wedung Kabupaten Demak. Langkah selanjutnya adalah penyuluhan terhadap petambak Desa Mangkang Wetan dan
Mangunharjo tentang tata cara budidaya kerang di tambak. Tahapan penyuluhan meliputi tahapan dialok di ruangan dengan penyuluh menyampaikan materi tentang budidaya kerang serta permasalahnya. Kemudian dilanjutkan dengan kunjungan lapangan dengan petambak kerang yang telah berhasil.

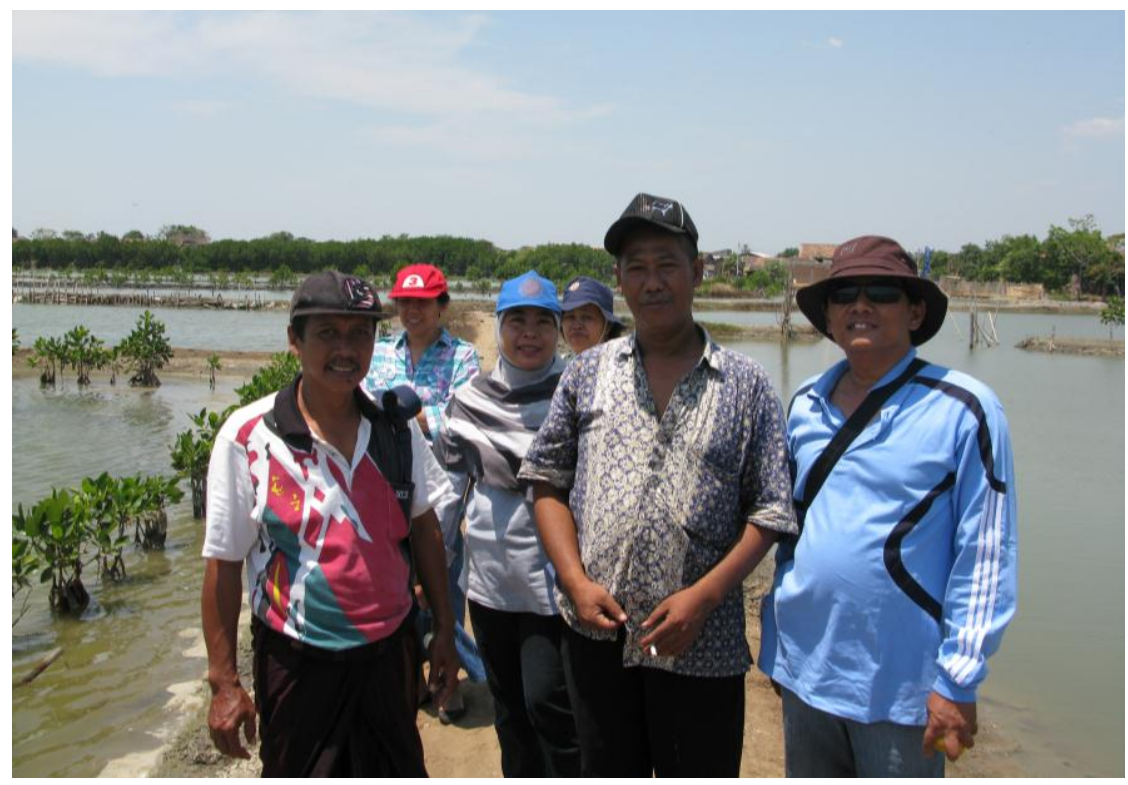

Gambar 1. Foto survey di pertambakan di Desa Mangkang Wetan dan Mangunharjo Kecamatan Tugu Kota Semarang

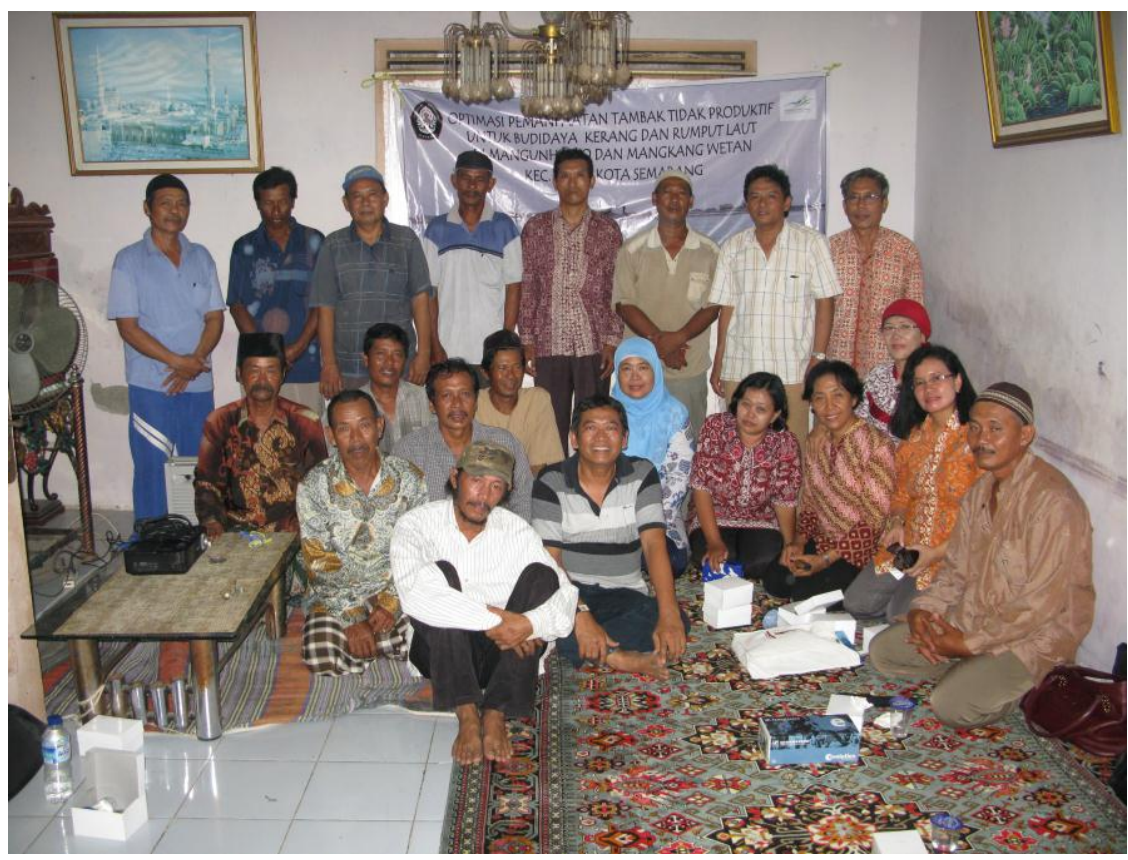

Gambar 2. Foto kegiatan penyuluhan budidaya kerang di Desa Mangkang Wetan dan Mangunharjo Kecamatan Tugu Kota Semarang 
Hasil penyuluhan menunjukan masyarakat Desa Mangkang Wetan dan Mangunharjo Kecamatan Tugu Kota Semarang sangat antusias untuk buidaya kerang, hal tersebut disebabkan permintaan pasar yang tinggi untuk kerang darah dan harga yang menguntungkan. Harga kerang di pasar ikan Kobong Semarang antara Rp 8.000 Rp 17.000 tergantung ukuranya. Antusias petambak tinggi bila komoditas yang dihasilkanya mudah menjualnya dan memiliki nilai tinggi sedangkan ongkos produksinya murah dan mudah. Karena dalam budidaya kerang tidak diperlukan perawatan dan pakan sedangkan panen dapat dilakukan kapan saja tergantung kebuuhan. Manfaat lain dari budidaya kerang ditambak adalah dapat berfungsi sebagai biofilter alami karena kerang darah cara mendapatkan makanannya dengan cara menghisap lumpur yang ada di dasar tambak sehingga sisa sisa pakan udang yang merupakan racun bagi tambak dapat terserap.

Setelah dilakukan penyuluhan baik tatap muka dengan ceramah maupun kunjungan lapangan ke petani tambak kerang di Desa Menco Demak. Petambak di Desa Mangkang Wetan dan Mangunharjo semakin percaya diri untuk budidaya kerang. Selama ini tambak di daerah tersebut dibiarkan bero (tidak dimanfaatkan secara optimal) karena tambak telah terkontaminasi oleh berbagai limbah baik dari kawasan industri maupun sisa sisa pakan udang dan pestisida di masa lalu. Dengan adanya kegiatan ini menimbulkan gairah petambak untuk berusaha terlebih saat musim kemarau dimana salinitas dan suhu air tambak relatif tinggi sehingga tidak cocok untuk budidaya udang maupun bandeng.

Hasil penebaran penebaran kerang menunjukan pertumbuhan yang nyata selama 3 bulan seperti terlhoat di grafik dibawah ini. Dari sampel kerang sebanyak 12 ekor dengan berat rata rata 3,6 gram pada awal penebaran bulan Agustus, meningkat menjadi rata rata 6,8 gram pada bulan September dan menjadi 15,6 gram pada bulan Oktober dengan peningkatan rata rata perbulan 6 gram. Pertumbuhan kerang tersebut relatif sangat cepat hal tersebut dimungkinkan daerah tersebut belum pernah digunakan untuk budidaya kerang sehingga kandungan bahan organik yang ada didasar tambak sangat banyak dan hal tersebut sangat baik untuk pertumbuhan kerang. Karena kerang makanannya adalah bahan organik yang terdapat dalam subtrat dasar perairan. Pertumuhan keang tersebut lebih cepat bila dibandingkan dengan kerang yang dipelihara di Tegal yang kandungan bahan organiknya lebih rendah (Djunaedi, dkk,.2005).

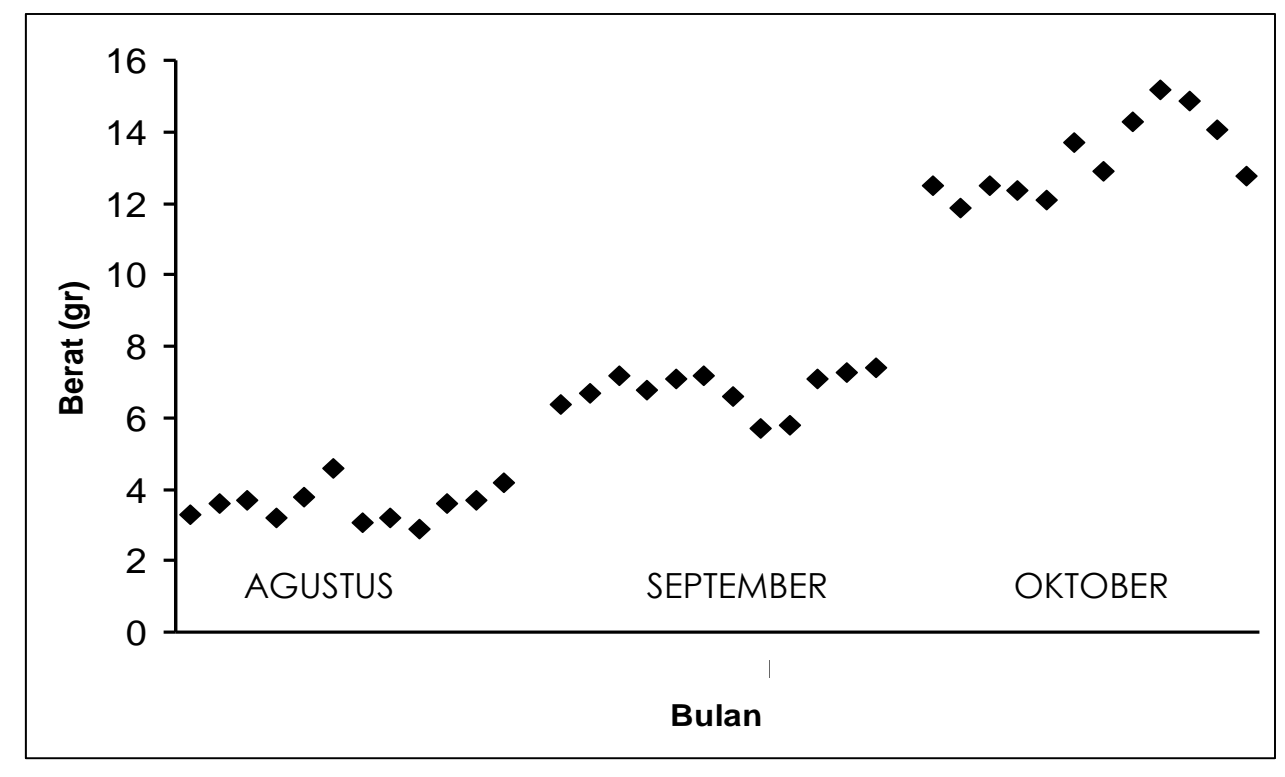

Gambar 3. Grafik pertumbuhan kerang darah yang dipelihara di tambak Desa Mangkang Wetan dan Mangunharjo selama tiga bulan 

Keseluruhan hasil kegiatan pengabdian masyarakat diatas menunjukkan bahwa masyarakat di Desa Mangkang Wetan dan Mangunharjo yang mengandalkan tambak sebagai sumber mencari penghasilan sangat tertarik pada suatu cara baru atau informasi yang sifatnya inovatif, hal inilah yang merupakan faktor pendorong kegiatan tersebut. Maka dari itu budidaya kerang di desa tersebut sangat produktip dan menguntungkan dan dapat dijadika percontohan untuk tambak tambak lain disekitar daerah tersebut.

\section{Ucapan Terimakasih}

Dalam kesempatan ini penuli mengucapkan terimakasih kepada Dirjen Dikti, LLPM Undip dan Fakultas Perikanan dan IImu Kelautan yang telah membiyayai kegiatan pengabdian masyarakat dengan judul IbM Pelestari Mangrove dan Budidaya Kerang darah di Kota Semarang dari dana Anggaran 2014, melalui DIPA UNDIP Nomor DIPA: 023.04.2.189185/2014.

\section{Daftar Pustaka}

Anonymous, 1984. Introducing the tilapia. INLARM News Letter, 7(1):3-6.

Asnan, M., Hariati, A. M., Gede, D., Wiadnya, R dan Surjowardoyo. 1998.
Penerapan paket teknologi polikulture : itik - nila - lele dumbo sebagai alternatif sumberdaya ekonomi pedesaan. Prociding Seminar Nasional Hasil Vucer dan Ipteks. Cisarua. Hal : $383-391$

Bardach, J. E., Ryther, H. H and McLarney, W. O. 1976. Aquaculture, The farming and husbandry of freshwater and marine organisms. Willey Intersciences. New York. 734 - 759 pp.

Chrisna, A.S., Irwani, Djunaedi,A,. 2011. IbM Kelompok Pelestari Mangrove dan Pembesaran Kepiting di Kota Tegal. Laporan Pengabdian Mansyarakat Program IbM

Junaedi, A. Imwani, Chrisna, A.S. 2005.,Pengembangan dan Pemanfaatan Tambak Tidak Produktip untuk Budidaya Kerang (Anadara granosa) Sebagai Upaya Pemanfaatan Hasil Tangkapan Kerang yang Tidak Termanfaatkan di Desa Muara Reja Kecamatan Tegal, Kota Tegal. Laporan Pengabdian Kepada Masyarakat Program Iptek

Kusnendar, E dan Sudjiharno, 1999. Polikulture bandeng dan udang di tambak. Balai Budidaya Air Payau. Jepara.

Laverack, M. S and Danda, J. 1974. Texbook of zoology invertebrate. The McMilan Press. New York. 874 p. 